Document de Recherche du Laboratoire d'Économie d'Orléans

DR LEO 2016-13

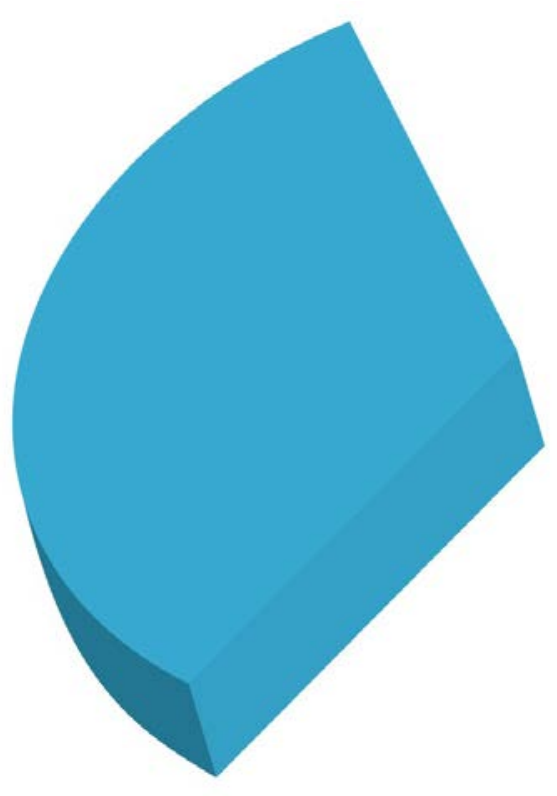

Archival data of financial analysts' earnings forecast in the euro zone: problems with euro conversions

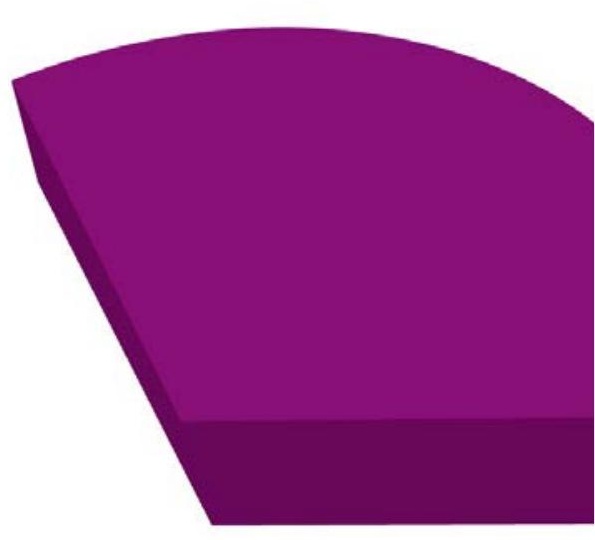

Sébastien GALANTI

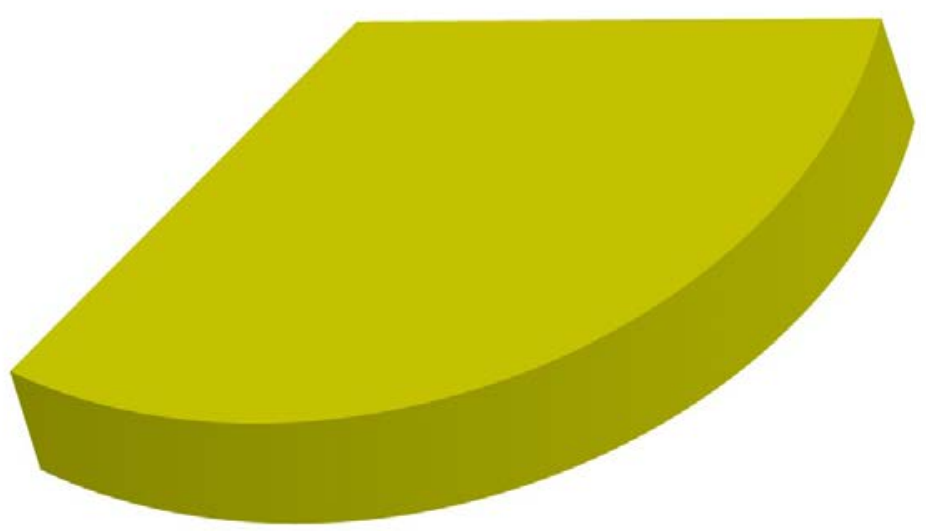




\title{
Archival data of financial analysts' earnings forecasts in the euro zone: problems with euro conversions
}

\author{
Sébastien Galanti ${ }^{1}$ \\ Univ. Orléans, CNRS, LEO, UMR 7322, rue de Blois, F-45067, Orléans, France.
}

\begin{abstract}
In multi-country studies, researchers frequently extract data in a single currency rather than in native currencies. This approach can be misleading for financial analysts' forecasts in the euro zone when researchers are using the IBES database. We suspect that forecasts of earnings before the birth of the euro on January 1, 1999 are kept in national currencies, although they are supposed to be displayed in euros, which can severely distort results concerning earnings forecast accuracy. We propose a simple procedure for checking for the existence of this error, as well as a quick solution to overcome it.
\end{abstract}

Keywords:

Earnings per Share

Earnings Forecasts

Security Analysts

IBES database

Forecasts accuracy

Microeconomic data

JEL classification:

C18

C55

C81

G14

G24

\footnotetext{
${ }^{1}$ E-mail address: sebastien.galanti@univ-orleans.fr
} 


\section{Introduction}

Economics scholars routinely extract data from database provider interfaces, such as Datastream, Bloomberg or ThomsonReuters. These interfaces always propose extracting monetary data in native currencies or in certain specified currencies. It seems that data from the IBES database concerning security analysts' earnings forecasts face a problem linked to the formation of the European monetary union.

On Jan. 1, 1999, national currencies of countries included in the European Monetary Union were merged according to specified exchanged rates. All bank money and deposits were converted to euros. When extracting archival data today in euros, monetary amounts from before 1999 are converted to euros.

By focusing on the accuracy of analysts' forecasts, researchers compute the "forecast error" as the difference between forecasted earnings and realized earnings. Because these forecasts are considered to be a proxy for market expectations, there is a vast amount of relevant literature (see e.g., Ramnath et al. 2008). In particular, analysts’ forecasts are of interest to firms (Siougle et al. 2014) and investors (Arjoon et al. 2016), and remain the best forecasts available (Gavious and Parmet 2010).

In the literature, analysts' forecasts data very often come from the international IBES database. We show that pre-euro forecast data in IBES are not correctly converted to euros. This leads to a large over-estimation of forecast errors for analysts in the euro zone before 1999. We want to alert researchers to this phenomenon and propose a simple way to detect this conversion error. We show that re-converted data can display much more consistent forecast errors that are comparable to forecast errors in the US, UK and Japan.

There is a large amount of literature scrutinizing earnings forecast errors, although mostly regarding US data. Still, numerous articles use IBES to analyse European countries and include the pre-euro period. To cite just a few, Hovakimian and Saenyasiri (2014) start in 1991 and include 11 of the 15 countries using the euro, ${ }^{2}$ Basu et al. (1998) include three countries from the euro zone for the period of 1987-1994, Capstaff et al. (2001) include seven over the same period, and Barniv et al. (2010) include eight between 1993-2007. Moreover, Glaum et al. (2013) focus

\footnotetext{
${ }^{2}$ There were 11 countries in the euro zone at the birth of the euro in 1999 and 19 countries in 2015 . We focus on 1999 because the European countries in our database (France, Holland and Belgium) adopted the euro from the start. However, our warning may also apply for countries that adopted the Euro later on.
} 
on Germany between 1997-2005, and whereas Guedj and Bouchaud (2005) do not detail which European Union countries they studied, it is unlikely that no euro-zone countries are included for the 1987-2004 period they cover. They show that forecasts are, on average, over-optimistic and that this effect is "particularly strong in the early 1990s and the internet bubble”. Coën et al. (2009) include eight euro-zone countries between 1990-2006 and insists on the importance of country effects for forecast errors. ${ }^{3}$

These articles do not disclose the way in which they extracted the data (in native currencies, converted to USD or converted to euros), but in the cases where the data were converted, an overestimation of forecast errors for euro-zone countries before 1999 is very likely. However, those articles provide neither explicit yearly analyses nor year dummies, and as a result, we cannot not be sure that they suffer from this conversion problem. Therefore, we warn researchers to check the conversion problem before conducting their studies about earnings forecasts.

This article also adds to the literature about misreported data, with a focus on IBES. Ljungqvist et al. (2009) compare data downloaded in different years and document a large number of ex-post changes about recommendation records. Cheong and Thomas (2011) describe several caveats in their Section 2.1 (e.g., one firm-Berkshire Hathaway-have per-share forecast errors higher than $\$ 400$, with the next-highest forecast error in their sample is $\$ 11$ ). Jeegadesh and Kim (2006, section 5.1) also question the dates in which recommendations were released. Ertimur et al. (2011) remind us that analysts voluntarily provide information to IBES and show that what information they disclose depends on concerns about their reputations. Hoechle et al. (2015) scrutinize time stamps and show that earnings or recommendations dates are often delayed by two to four trading days.

The structure of the remaining parts of the paper is as follows. Section 2 investigates the impact of the conversion problem on the related literature. We then present our data and methodology in Section 3. In Section 4, we show that the original data display conspicuously large forecast errors for the euro-zone countries of our study. Section 5 presents our results for when earnings forecasts and stock prices are re-converted, and Section 6 presents our conclusion.

\section{The impact on the related literature}

\footnotetext{
${ }^{3}$ On the contrary, studies that include countries after they adopted the Euro are, in principle, not subject to the conversion problem.
} 
To assess how financial literature can be impacted, take the following example. Suppose first that data are in a given national currency (e.g., French Francs). The analyst' forecast is $F=3$, but the actual earnings are $E=2.5$. We can compute the difference between the two, or the "unscaled" forecast error, as $F E=0.50$, and the forecast error scaled by earnings ( $F E / E=$ $20 \%)$. With stock price $P=15$, we compute the forecast error scaled by the price $(F E / P=3.33 \%)$.

Now suppose that one extracts data in Euro currency, to compare pre- and post-euro periods. The same observation would appear as (with the FRF/EUR exchange rate, rounded numbers): $F=0.46, E=0.38, P=2.29$, with which we compute $F E=0.08, F E / E=20 \%$ and $F E / P=$ $3.33 \%$.

Scaled measures of forecast errors are unchanged, and the unscaled measure (FE) is logically modified. However, this can be a problem if the database incorrectly displays the data in the national currency. For example, say the researcher asks for data in euros, and the forecast is displayed as " $F=3$." It is supposed to be in euros, but it is actually in the national currency (3 French Francs). Then, without further examination, the unscaled measure of forecast error would be over-estimated ( 0.50 instead of 0.08 ). This would bias pre- and post-euro comparisons, along with cross-country comparisons. However, scaled measures remain unbiased.

However, suppose that the researcher takes the forecast $F$ from this flawed database and the earnings $E$ from another database which correctly converts the currencies. Then, even scaled measures are incorrect ${ }^{4}$. If the exchange rate of the national currency against one euro is above 1 , forecast errors are over-estimated ${ }^{5}$.

This hypothetical example helps to assess the conditions under which an article could potentially be affected by the conversion problem:

(1) Earnings forecasts $F$ are extracted from IBES after Jan. 1, 1999 and include pre-euro data from a country involved in the European Monetary Union.

(2) The study uses unscaled FE and earnings $E$ from IBES, and either (A) also includes post-euro data or (B) is restricted to the pre-euro period and makes cross-country comparisons.

\footnotetext{
${ }^{4}$ With $F=3$ and $P=15$ but $E=0.38$, this would yield $F E=2.62, F E / E=687 \%$ and $F E / P=17.5 \%$.

${ }^{5}$ It is the case of every country in the euro zone, expect Ireland (1999), Cyprus and Malta (2008) and Latvia (2014).
} 
(3) The study uses actual earnings $E$ from another correctly converted database, and also includes post-euro data.

(4) The study uses scaled measure $F E / P$ and earnings $E$ are from IBES and also includes post-euro data, but stock prices $P$ come from another correctly converted database.

Condition (1) is necessary, while conditions (2), (3) and (4) are mutually exclusive. The problem arises when (1) is combined with one of the three others.

Some articles are immunized against the conversion problem. Basu et al. (1998) used forecasts from IBES and earnings from Compustat, but they obviously extracted the data before 1999. Another example is the article of Captstaff et al. (2001), which was received by the journal in January 2000. It includes data for seven European countries from 1987-1994 as well as earnings data from IBES, but the authors used scaled (FE/E) measures. Finally, Hovakiman and Saenyasiri (2014) include data for 11 euro countries for 1991-2010 and use scaled (FE/P) measures, but earnings and price data also came from IBES.

Other articles are susceptible to this conversion problem. It is generally difficult to assess the precise impact of the conversion problem on the results, and we cannot be sure that the problem actually occurred (because the currency in which data are extracted is never given). However, we can state that the results are potentially affected. Peek (2005) analysed data for the Netherlands from 1988-2001, with prices coming from Datastream. As the author used accuracy measures scaled by price, the conversion problem potentially applies. The author finds that forecast accuracy is influenced by the year when accounting changes occur. Barniv et al. (2005) use unscaled measures for 1984-2001. Countries are grouped by legal systems (“French-origin”, "German-origin”, etc.), and although their composition is not given, it is unlikely that they do not include countries from the euro zone. They find that in civil-law countries, analysts provide accurate forecasts less consistently than in common law countries. McKnight et al. (2010) include seven countries from the euro zone in their study for 1988-2005, and use measures scaled by price. Is it not specified whether the source for earnings and price is IBES or SDC. Their Table VI splits the sample by country over the whole period. Although the authors find that biases in earnings forecasts concerning underwritten relationships are not driven by one particular country, if the conversion problem applies, it should affect the average forecast errors. The problem may also affect meta-analyses reviewing the financial literature, such as in Garcia-Meca and Sanchez-Ballesta (2006). Only 6 articles out of 38 include years and countries affected by the 
Euro, but they conclude that countries and time periods "moderate the effects of some characteristics on analysts' accuracy," which is consistent with our thesis. For example, they cite the study of Bolliger (2004), which includes eight euro-zone countries from the period of 19881999 and uses both unscaled measures such as the PMAFE (à la Clement, 2003) and measures scaled by price (source not specified). The mean $F E / P$ is relatively large (2.48\%) and compares with our pre-euro figures (Table 1 in subsequent section 4) for France, Netherlands and Brussels, but does not compare with post-euro figures (rather approximately 1\%). The author finds an association between forecast accuracy and some, but not all, analyst characteristics commonly used in articles using US data. Coën et al. (2009) include eight euro countries for 1990-2006 and study accuracy measures scaled by earnings. Like Basu et al. (1998) and Capstaff et al. (2001), the authors choose to apply a sharp cut-off, dropping all variables for which the absolute $F E$ is above $100 \%$. In doing so, they likely bypass many of the outliers generated by the potential conversion problem. However, although the European countries do not have the most extreme forecast errors on average over the whole period, the authors show that country effects dominate the industry and many analyst effects (see their Table 3a). They find that the types of earnings are the most influential on forecast accuracy. Barniv et al. (2010) includes data on eight euro-zone countries from 1993-2007. The forecasts are included in valuation models, so it follows that some firm valuations can be over-estimated if forecasts are incorrectly converted. Although the analysis takes into account year fixed-effects that can account for some of the conversion problem, the authors run country-level analyses showing that some euro-zone countries have significant coefficients (results not tabulated, p.1159 et sq.). This study concludes that the association between valuations and future stock returns depend on whether the country has low or high investor participation. In other articles, descriptive statistics seem to be in line with the euro conversion problem. In Guedj and Bouchaud (2005), the authors include the US, UK, Japan and "EU stocks" without precision from 1987-2004, and use unscaled measures of accuracy. In particular, they show that analysts' optimistic biases are time-dependent, and "larger in the EU than for S\&P stocks” (p.938), although EU stocks include the UK. Clement et al. (2003) use data from 1995-2000, including 5 European countries. Descriptive statistics (see their table 4) of scaled median forecast errors show that "the least accurate forecasts are for German (0.40) and French firms (0.39)” when compared to the US (0.05) and UK (0.06). The rankings are almost the same with the mean forecast errors. Finally, Glaum et al. study data for Germany from 1997- 
2005 and show that the mean (absolute) forecast error scaled by price is $10.4 \%$, which is relatively large (see their table 3 ). The median is only $2.2 \%$, suggesting that the measure could be influenced by outliers.

\section{Data and methodology}

Our initial database spans from January 1993 to December 2011 and comprises firms listed on the NYSE 100, NIKKEI 100, FTSE100, and Euronext100 indexes. The latter includes stocks from the Paris, Amsterdam, Brussels and Lisbon Stock Exchanges. We removed firms for which several items were missing, as well as cross-listed firms. In total, we included 85 firms in New York, 93 in Tokyo, 87 in London, 64 in Paris, 18 in Amsterdam and 11 in Brussels. With only 5 firms, Lisbon was removed from our data because of insufficient pre-1999 data. We were left with 417,168 firm-month-forecast observations.

We focus on analysts' 1-year-ahead earnings per share forecasts about these firms (item ibh.epsestimatevalueFYR1), the actual earnings per share of the firms (item ws.eps), and their price (ibh.priceclose). The data were downloaded in January 2012 using the ThomsonReuters web interface, which obtains data from IBES Historical files (prefix $i b h$ ), Worldscope data (prefix ws) and many other sources. Note that forecasts and prices were from the IBES while earnings were not. For all data, including non-euro countries, the currency parameter was set as "eur".

To obtain a quick, broad picture, we aggregated the variables at the market level. The forecast error $(F E)$ is the difference between the earnings forecast $F$ and the realized earnings $E$. We first computed the monthly average forecast for firm $j$, newly issued at month $m$ in stock exchange $s$, and subtract the actual target earnings to obtain the average forecast $\operatorname{error}^{6} F E_{j, s, m}$. We then took the monthly average of $F E_{j, s, m}$ at the market level for stock exchange $s, F E_{s, m}$, when there is at least one forecast for the firm for that month.

\footnotetext{
${ }^{6}$ We studied annual earnings, although we kept the $m$ index for notational convenience. For example, supposing a firm for which the fiscal year ends on December 31, and that earnings of $1.50 €$ are announced in February 2006, we recorded the earnings targeted for month $2005 \mathrm{~m} 5$ or $2005 \mathrm{~m} 9$ as $1.50 €$. If $0.80 €$ was announced in February 2007, then the actual earnings targeted in $2006 \mathrm{~m} 6$ would be $0.80 €$, etc. We checked for earnings announcements and forecast daily dates in order to build consistent forecast errors (when forecast and earnings are announced on the same month, etc.). Also see Hovakimian and Saenyasiri (2010) on this point.
} 


$$
F E_{s, m}=\frac{1}{J_{s, m}} \sum_{j} F_{j, s, m}-E_{j, s, m}
$$

We now refer to this measure as the "forecast error" or the "unscaled forecast error". To have comparable magnitudes (as discussed in Cheong and Thomas, 2011), we also used a measure scaled by the stock price of the firm, $P_{j, s, m}$ :

$$
F E_{s, m}=\frac{1}{J_{s, m}} \sum_{j}\left(F_{j, s, m}-E_{j, s, m}\right) / P_{j, s, m}
$$

We refer to the measure in Eq. 2 as the "scaled forecast error". The monthly stock price is the closing price reported by IBES (the last available prices from the Thursday before the third Friday of every month). Finally, we used the same market-level averages for forecasts, earnings, and prices.

Then, we chose to winsorise those variables at the firm-analyst level to prevent aggregated data from being biased by outliers. We set the level at $1 \%{ }^{7}$ which is smaller than the $2 \%$ of Brav and Lehavy (2003) and Gerritsen (2015, see Section 2.2).

\section{Forecast accuracy without corrections}

A glance at Figure 1 shows the extent of the problem.

\section{[FIGURE 1 HERE]}

In all four areas, forecasts are quite optimistic during the "slow crash" of the dot-com bubble (2001-2003), when analysts gradually adjusted their forecasts downwards. The forecast errors are, once more, quite large during the Global Financial Crisis of 2007-2009 (between 1 and 2.5 euros). As a result, the evolution of the market indexes may explain a substantial part of the forecast errors of these periods, even in Japan, where the trend was oriented downward

\footnotetext{
${ }^{7}$ This means $0.5 \%$ of the sample at each tail, for earnings, forecasts, and forecast errors. For closing prices, the level is $5 \%$ (upper tail only) because of very large prices for some firms in certain years.
} 
throughout the entire 1993-2011 period. Excluding those periods of time, the level of forecast errors seem to be quite stable (lying between 0 and 0.5 euros), and they are sometimes slightly pessimistic (negative errors). London, however, was an exception, as optimism seemed to be higher on average there in the early 2000s.

However, a visible break in the Euronext series happens in January 1999. Whereas the FE is high until December 1998 (approximately 4 to 5.5 euros, much larger than other places), it suddenly drops towards zero and stays low for the rest of the period. Even during the Global Financial Crisis -an event with a rare magnitude - FEs are much smaller (approximately 1.5 euros). The Euronext 100 index does not seem to replicate such a break at the same time.

Table 1 confirms the visual impression from the previous figure. For Paris, Amsterdam and Brussels, as opposed to New York, London and Tokyo, we find no real difference in realized earnings. On the contrary, for forecasts, forecast errors, and prices, the former group experienced high pre-Euro levels compare to post-Euro levels, which yields a negative variation rate between the two periods. The result is completely different for the latter group, for which this rate is higher than $100 \%$ in most cases. ${ }^{8}$

\section{[TABLE 1 ABOUT HERE]}

This is why we hypothesize that forecasts are probably kept in national currencies even they are supposed to be in euros in the database. The rest of this paper aims to show that this hypothesis is plausible. On the contrary, the chances that some macro-event caused the break in the Forecast Error series seem very unlikely. No particular financial reform or monetary policy changed drastically during that time; the only change that occurred was that on January 1, 1999, national currencies were replaced by the Euro as a unit of account in all payments and, of course, on the stock exchanges.

In the next section, we re-convert the pre-1999 forecasts, prices and forecast errors data and show that these new re-converted series are much more plausible.

\footnotetext{
${ }^{8}$ We suspect another problem concerning Japanese firms. Their prices do not seem to follow the Nikkei index shown in Figure 1. Most firms have prices in euros between 1 and 10, while others have prices higher than 200 (like Kyocera, TDK Fanuc, etc.), which matches their prices in yen (with the exchange rate around 100 yen for 1 euro in late 2011). It is far beyond the scope of this short paper to explore this problem, but this finding further strengthens our warning to check conversion problems in IBES.
} 


\section{Forecast accuracy with re-conversion of currencies}

We divide forecasts, forecast errors and prices for firms listed in Paris, Amsterdam and Brussels by 6.55957 for the French franc, 2.20371 for the Dutch guilder, and 40.3399 for the Belgian franc, respectively. We then compute the variation before and after the Euro again, as in Table 1. Table 2 shows this comparison.

\section{[TABLE 2 HERE]}

Columns 1, 3 and 4 summarize the previous table. Comparing Columns 2 and 5 with the corresponding figures for the non-Euro group (Columns 1 and 4) yields the same levels of forecasts, forecast errors (scaled or unscaled) and prices. The averages are closer to 1 euro, and the forecast errors are closer to zero. We now find a stock price evolution that is more consistent with the Euronext 100 index of Figure 1. Unsurprisingly, the magnitude of the adjustment depends on the exchange rate: it is more (less) important for Belgium (Holland), for which the rate is 40.3 (2.2) for 1 euro.

To develop this point, we studied the evolution of forecast errors from one month to another in terms of absolute variation and analysed the deviation from the sample mean. If we are correct, January 1999 should be a peak for the three Euro countries with the conversion problem (FE artificially high in December 1998 and then suddenly low in January 1999, which entails a high absolute variation). Once re-converted, this month should not appear as the most extreme outlier.

Figure 2 confirms this hypothesis. ${ }^{9}$ Whereas January 1999 is the most extreme observation for all three exchanges for the raw data supposed to be in euros, this is no longer the case when the series are re-converted: the maximum market-level change in forecast errors is in February 2008 (Paris), March 2008 (Amsterdam) and May 2011 (Brussels). This result seems more

\footnotetext{
${ }^{9}$ We find the same qualitative result using the scaled forecast error as in Eq. (2), which is available from the author upon request. A close look at Figure 2 shows that January 1999 still is an important value. This result is due, especially in Brussels, to the small number of firms in our database around 1998 and 2000 (6 Belgian firms as of Dec. 1998): this finding implies that the market average is too dependent on this small number of firms. However, it does not invalidate our overall findings regarding the conversion problem because this exercise can be done at the firm level. At the firm level, this averaging problem disappears (we analyse the market level for brevity).
} 
consistent with intuition, given the magnitude of the 2007-08 crisis and the sovereign debt crisis in the euro zone (2011). Computing the odds of these events would show that those crises were unlikely in the statistical sense (six to eight standard deviations away from the mean). However, the break of January 1999 would be even less likely (six to twelve standard deviations away from the mean).

\section{[FIGURE 2 HERE]}

We therefore conclude that the most plausible scenario is that the forecast series provided by IBES, which is supposed to be in euros, was in fact not converted (e.g., $5 €$ are in fact 5FRF) before 1999.

\section{Conclusion}

This article aims to alert researchers about a conversion error for data from the IBES database, at least for earnings forecasts and stock prices. We present a simple way to detect this error. We hope that future research about earnings forecasts that includes countries before and after they joined the euro zone will benefit from this warning. As long as the exchange rate is far from parity, forecast errors will be largely misestimated. Re-converting data, using euro exchange rates for individual countries, results in much more consistent and plausible forecast accuracy and stock prices.

\section{Acknowledgements}

The author thanks Yvan Stroppa and Philippe Hurlin for their constructive feedback and help in the data management and data collection processes. We thank the participants at a research seminar at the University of Orléans for their remarks and Anne-Gaël Vaubourg, Raphaëlle Bellando, Michel Dubois, Tristan Roger and Régis Breton for the valuable discussions. Data from I/B/E/S and Worldscope were provided by ThomsonFinancial as part of an academic programme to encourage research. 


\section{References}

Arjoon V, Bougheas S, Milner C. 2016. Lead-lag relationship in an embryonic stock market: exploring the role of institutional ownership and quality. Research in International Business and Finance, 38, 262-276.

Barniv R, Myring M, Thomas W. 2005. The association between legal and financial reporting environments and forecast performance of individual analysts. Contemporary Accounting Research 22(4), 727-758.

Barniv R, Hope OK, Myring M, Thomas W. 2010. International evidence on analyst stock recommendations, valuations, and returns. Contemporary Accounting Research 27(4), 1131-1167.

Basu S, Hwang LS, Jan CL. 1998. International variation in accounting measurement rules and analysts’ earnings forecast errors. Journal of Business Finance and Accounting 25(9) \& (10), 1207-1247.

Bolliger, G. 2004. The characteristics of individual analysts’ forecasts in Europe. Journal of Banking and Finance, 28, 2283-2309.

Brav A, Lehavy R. 2003. An empirical analysis of analysts’ target prices: short-term informativeness and long-term dynamics. Journal of Finance 58 (5), 1933-1967.

Capstaff J, Paudyal K, Rees W. 2001. A comparative analysis of earnings forecasts in Europe. Journal of Business Finance and Accounting 28(5) \& (6), 531-562.

Cheong FS, Thomas J. 2011. Why do EPS forecast error and dispersion not vary with scale? Implications for analyst and managerial behavior. Journal of Accounting Research 49(2), 359-401.

Clement, M, Rees, L, Swanson, EP. 2003. The influence of culture and corporate governance on the characteristics that distinguish superior analysts. Journal of Accounting, Auditing and Finance, 18(4), 593-618.

Coën A, Desfleurs A, L'Her JF. 2009. International evidence on the relative importance of the determionants of earnings forecast accuracy. Journal of Economics and Business 61, 453-471.

Ertimur Y, Mayew W, Stubben SR. 2011. Analyst reputation and the issuance of disaggregated earnings forecasts to I/B/E/S. Review of Accounting Studies 16, 29-58.

Garcia-Meca E, Sanchez-Ballesta JP. 2006. Influences on financial analysts forecast errors : a meta-analysis. International Business Review, 15, 29-52.

Gavious I, Parmet Y. 2010. Do private firms valuation contain incremental information content over routine analyst valuations? Research in International Business and Finance, 24(2), 223-234.

Gerritsen DF. 2015. Security analysts’ target prices and takeover premiums. Finance Research Letters 13, $205-213$.

Glaum M, Baetge J, Grothe A, Oberdörster T. 2013. Introduction of international accounting standards, disclosure quality and accuracy of analysts’ earnings forecasts. European Accounting Review 22(1), 79-116.

Guedj O, Bouchaud JP. 2005. Experts’ earnings forecasts : bias, herding and gossamer information. International Journal of Theoretical and Applied Finance 8(7), 933-946.

Hoechle D, Schaub N, Schmid M. 2015. Time stamp errors and the stock price reaction to analyst recommendation and forecast revision. Working Papers on Finance N²012/15, University of St.Gallen. 
Hovakimian A, Saenyasiri E. 2010. Conflict of interest and analyst behavior: evidence from recent changes in regulation. Financial Analysts Journal 66(4), 96-107.

Hovakimian A, Saenyasiri E. 2014. US analyst regulation and the earnings forecast bias around the world. European Financial Management 20(3), 435-461.

Jegadeesh N, Kim W. 2006. Value of analyst recommendations: international evidence. Journal of Financial Markets 9, 274-309.

Ljungqvist A, Malloy C, Marston F. 2009. Rewriting history. Journal of Finance 64(4), 1935-1960.

McKnight P, Tavakoli M, Weir C. 2010. Underwriting relationship and analyst independence in Europe. Financial Markets, Institutions and Instruments 19(3), 189-213.

Peek, E. 2005. The influence of accounting changes on financial analysts' forecast accuracy and forecasting superiority: evidence from the Netherlands. European Accounting Review 14(2), 261-295.

Ramnath S, Rock S, Shane P. The financial analyst forecasting literature: a taxonomy with suggestions for further research. International Journal of Forecasting, 24, 34-75.

Siougle G, Spyrou SI, Tsekrekos AE. 2014. Conference calls around mergers and acquisitions: do they reduce information asymmetry? UK evidence. Research in International Business and Finance, 30, 148-172. 

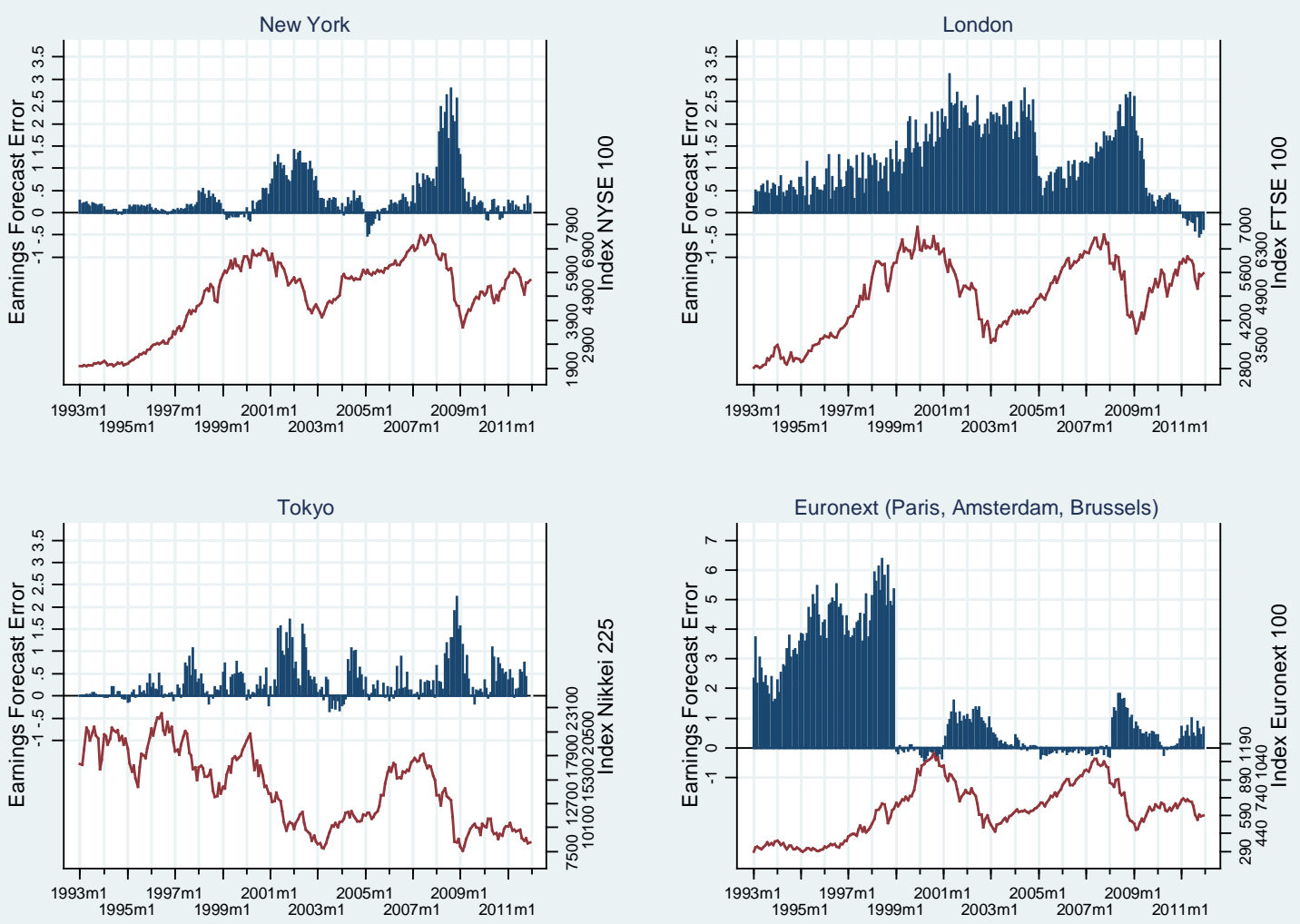

Figure 1. Earnings Forecast Errors, monthly averages as of Eq. (1) for firms listed at New York (upper left), London (upper right), Tokyo (lower left) and Euronext (lower right, contains firms listed at Paris, Amsterdam and Brussels). The size of forecast errors is given by the bars on the upper part of each graph and is displayed in euros (left scale). For comparison, the market indexes are from the Yahoo! Finance and NYSE websites and are represented by the lines on the lower part of each graph, displayed in points (right scale). 
Table 1. Descriptive statistics, with data as displayed.

\begin{tabular}{|c|c|c|c|c|c|c|c|}
\hline & $\begin{array}{l}\text { Before the } \\
\text { Euro }\end{array}$ & $\begin{array}{l}\text { After the } \\
\text { Euro }\end{array}$ & $\begin{array}{l}\text { After / } \\
\text { Before }\end{array}$ & & $\begin{array}{l}\text { Before the } \\
\text { Euro }\end{array}$ & $\begin{array}{l}\text { After the } \\
\text { Euro }\end{array}$ & $\begin{array}{l}\text { After / } \\
\text { Before }\end{array}$ \\
\hline \multicolumn{4}{|c|}{ Realized Earnings } & \multicolumn{4}{|c|}{ Earnings Forecasts } \\
\hline Paris & 0.99 & 2.48 & $151 \%$ & Paris & 5.89 & 2.59 & $-56 \%$ \\
\hline Amsterdam & 0.91 & 1.34 & $47 \%$ & Amsterdam & 1.79 & 1.65 & $-8 \%$ \\
\hline Brussels & 1.92 & 2.39 & $24 \%$ & Brussels & 28.07 & 2.53 & $-91 \%$ \\
\hline New York & 0.98 & 2.11 & $115 \%$ & New York & 1.16 & 2.59 & $123 \%$ \\
\hline London & 0.44 & 0.72 & $64 \%$ & London & 1.17 & 2.85 & $144 \%$ \\
\hline Tokyo & 0.7 & 1.72 & $146 \%$ & Tokyo & 1.53 & 4.24 & $177 \%$ \\
\hline \multicolumn{4}{|c|}{ Forecast Errors } & \multicolumn{4}{|l|}{ Stock Prices } \\
\hline Paris & 4.395 & 0.276 & $-94 \%$ & Paris & 157.7 & 44.8 & $-72 \%$ \\
\hline Amsterdam & 0.672 & 0.168 & $-75 \%$ & Amsterdam & 43.0 & 23,0 & $-47 \%$ \\
\hline Brussels & 12.300 & 0.268 & $-98 \%$ & Brussels & 968.7 & 35.4 & $-96 \%$ \\
\hline New York & 0.137 & 0.439 & $220 \%$ & New York & 19.5 & 41,0 & $110 \%$ \\
\hline London & 0.599 & 1.324 & $121 \%$ & London & 33.5 & 61.9 & $85 \%$ \\
\hline Tokyo & 0.138 & 0.438 & $217 \%$ & Tokyo & 11,7 & 16,5 & $41 \%$ \\
\hline \multicolumn{4}{|c|}{ Scaled Forecast Errors } & \multicolumn{4}{|c|}{ Nb. Firms (Nb. Obs.) } \\
\hline Paris & $2.99 \%$ & $0.77 \%$ & $-74 \%$ & Paris & $44(22,022)$ & $67(64,788)$ & - \\
\hline Amsterdam & $2.41 \%$ & $1.19 \%$ & $-51 \%$ & Amsterdam & $16(8,174)$ & $18(24,332)$ & - \\
\hline Brussels & $3.59 \%$ & $0.62 \%$ & $-83 \%$ & Brussels & $8(1,952)$ & $11(9,417)$ & - \\
\hline New York & $0.6 \%$ & $1.17 \%$ & $95 \%$ & New York & $33(38,992)$ & $50(101,903)$ & - \\
\hline London & $0.69 \%$ & $1.84 \%$ & $167 \%$ & London & $38(13,667)$ & $60(61,482)$ & - \\
\hline Tokyo & $0.41 \%$ & $0.94 \%$ & $129 \%$ & Tokyo & $38(12,390)$ & $67(58,049)$ & - \\
\hline
\end{tabular}

This table shows the market-level averages of several variables depending on the period and the variation between the two periods. The period before the Euro is Jan. 1993-Dec. 1998 (72 months), and the period after the Euro is Jan. 1999-Dec. 2011 (156 months). Realized Earnings are the market-average annual Earnings Per Share (EPS) targeted by analysts. Earnings Forecasts are the market-average one-year EPS estimates from analysts. Forecast errors are the market average of the difference between the forecast and the realized earnings, which is not equal to the difference in average forecast and average earnings because of missing realized earnings for some observations. Stock Prices are the marketaverage closing prices. Scaled Forecast Errors are the market-average Forecast Errors divided by the closing price. Nb Firms is the number of firms used to compute the market averages. Nb Obs. is the number of observations used to compute the market averages. This sample has a total of 417,178 observations 
Table 2. Descriptive statistics, with re-converted data.

\begin{tabular}{|c|c|c|c|c|c|}
\hline & $\begin{array}{l}\text { Before the Euro, as } \\
\text { displayed (1) }\end{array}$ & $\begin{array}{l}\text { Before the Euro, re- } \\
\text { converted (2) }\end{array}$ & $\begin{array}{l}\text { After the } \\
\text { Euro (3) }\end{array}$ & $\begin{array}{l}\text { Growth rate, (1) } \\
\text { and (3) }\end{array}$ & $\begin{array}{c}\text { Growth rate, (2) } \\
\text { and (3) }\end{array}$ \\
\hline \multicolumn{6}{|c|}{ Earnings Forecasts } \\
\hline Paris & 5.89 & 0.87 & 2.59 & $-56 \%$ & $198 \%$ \\
\hline Amsterdam & 1.79 & 0.95 & 1.65 & $-8 \%$ & $74 \%$ \\
\hline Brussels & 28.07 & 1 & 2.53 & $-91 \%$ & $153 \%$ \\
\hline New York & 1.16 & - & 2.59 & $123 \%$ & - \\
\hline London & 1.17 & - & 2.85 & $144 \%$ & - \\
\hline Tokyo & 1.53 & - & 4.24 & $177 \%$ & - \\
\hline \multicolumn{6}{|c|}{ Forecast Errors } \\
\hline Paris & 4.395 & -0.141 & 0.276 & $-94 \%$ & $151 \%$ \\
\hline Amsterdam & 0.672 & -0.190 & 0.168 & $-75 \%$ & $213 \%$ \\
\hline Brussels & 12.300 & -1.210 & 0.268 & $-98 \%$ & $551 \%$ \\
\hline New York & 0.137 & - & 0.439 & $220 \%$ & - \\
\hline London & 0.599 & - & 1.324 & $121 \%$ & - \\
\hline Tokyo & 0.138 & - & 0.438 & $217 \%$ & - \\
\hline \multicolumn{6}{|c|}{ Scaled Forecast Errors } \\
\hline Paris & $2.99 \%$ & $-0.04 \%$ & $0.77 \%$ & $-74 \%$ & $105 \%$ \\
\hline Amsterdam & $2.41 \%$ & $-0.79 \%$ & $1.19 \%$ & $-51 \%$ & $166 \%$ \\
\hline Brussels & $3.59 \%$ & $-0.09 \%$ & $0.62 \%$ & $-83 \%$ & $115 \%$ \\
\hline New York & $0.6 \%$ & - & $1.17 \%$ & $95 \%$ & - \\
\hline London & $0.69 \%$ & - & $1.84 \%$ & $167 \%$ & - \\
\hline Tokyo & $0.41 \%$ & - & $0.94 \%$ & $129 \%$ & - \\
\hline \multicolumn{6}{|l|}{ Stock Prices } \\
\hline Paris & 157.7 & 17.0 & 44.8 & $-72 \%$ & $163 \%$ \\
\hline Amsterdam & 43.0 & 15.5 & 23.0 & $-47 \%$ & $48 \%$ \\
\hline Brussels & 968.7 & 24.2 & 35.4 & $-96 \%$ & $46 \%$ \\
\hline New York & 19.5 & - & 41,0 & $110 \%$ & - \\
\hline London & 33.5 & - & 61.9 & $85 \%$ & - \\
\hline Tokyo & 11,7 & - & 16,5 & $41 \%$ & - \\
\hline
\end{tabular}

The table shows the market-level averages of several variables depending on the period and the variation between the two periods. The period before the Euro is Jan. 1993-Dec. 1998 (72 months), and the period after the Euro is Jan. 1999-Dec. 2011 (156 months). Realized Earnings are the market-average annual Earnings Per Share (EPS) targeted by analysts. Earnings Forecasts are the market-average one-year EPS estimates from analysts. Forecast errors are the market average of the difference between the forecast and the realized earnings, which is not equal to the difference in average forecast and average earnings because of missing realized earnings for some observations. Scaled Forecast Errors are the market-average Forecast Errors divided by the closing price. Stock Prices are the market-average closing prices. We distinguish, for the Paris, Brussels, and Amsterdam Stock Exchanges, between data supposed to be in euros, as displayed by the database, and data re-converted by us according to the exchange rates of national currencies as of Jan. 1, 1999 (6.55957 FRF, 40.3399 BEF and 2.20371 NLG for 1 EUR). The sample has a total of 417,178 observations. 

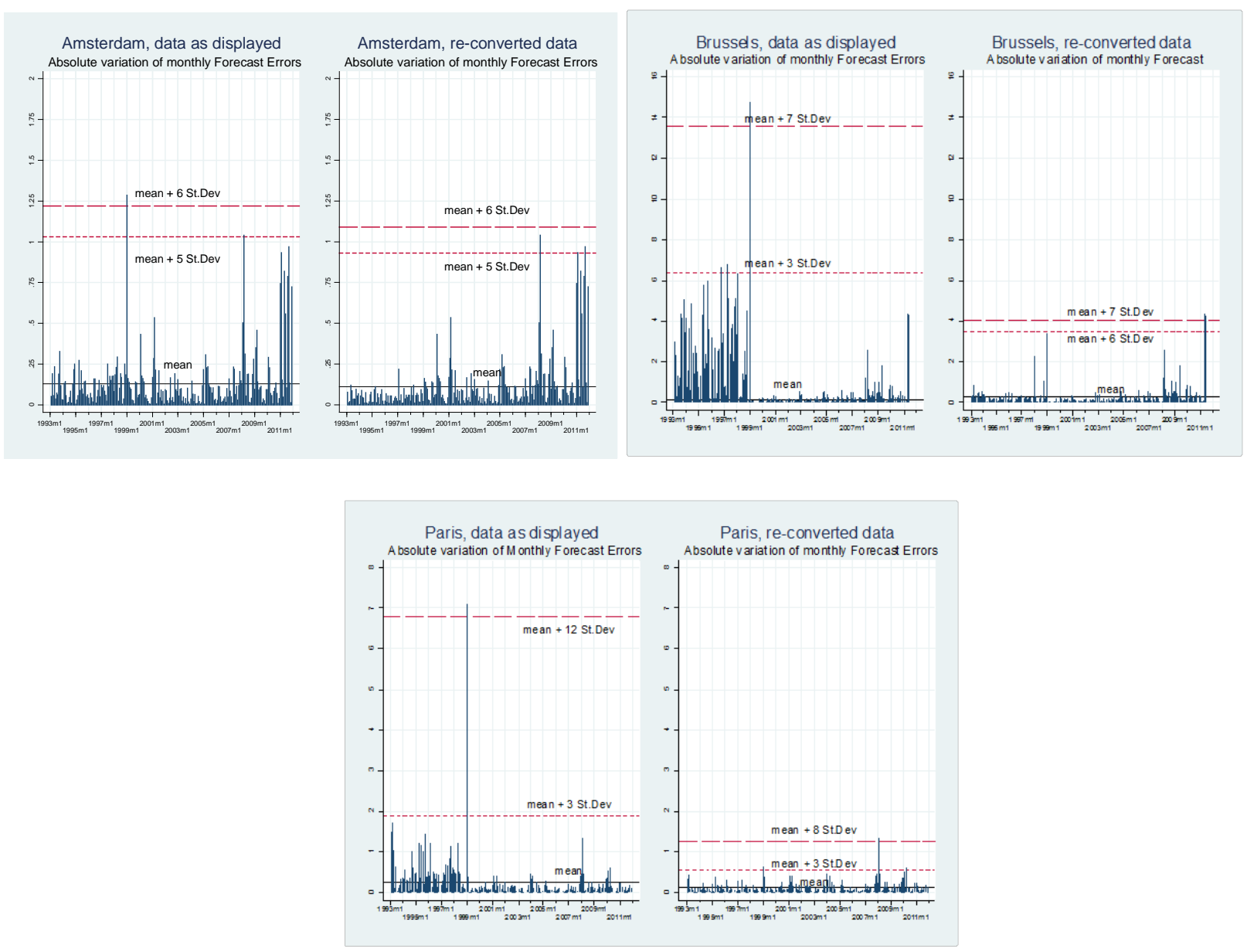

Figure 2. Earnings Forecast Errors as of Eq. (1), absolute variation in monthly averages, for firms listed in Amsterdam, Brussels and Paris. For each stock exchange, computation with data as displayed by IBES is on the left, and computation with data re-converted by the author is on the right. 